\author{
André Filipe dos Santos Leite \\ Universidade Federal de Sergipe
}

\author{
Thiago Ranniery Moreira de Oliveira \\ Universidade do Estado do Rio de Janeiro
}

\title{
Sobre educar médicas e médicos: marcas de gênero em um currículo de Medicina
}

Resumo: Este artigo investiga como normas de gênero marcam o funcionamento do discurso pedagógico da Medicina em um currículo de formação médica. A partir de observações participantes, somadas a uma linha de ação inspirada na analítica do discurso de Michel Foucault, argumenta-se que o currículo da Medicina é constituído por um conjunto de discursos que posicionam corpos generificados, articulados em torno tanto de uma medicalização da moralidade sexual como de uma moralização sexual da Medicina. Ao conectar reprodução, capacidades cognitivas e processos de cuidado em saúde a matrizes generificadas de relações, explora-se como as estratégias discursivas suplementam e transformam o horizonte médico, concebido como homogêneo e estável, em um jogo de significações que indicam que a Medicina, ou pelo menos a educação médica, talvez não seja tão biomédica assim.

Palavras-chave: currículo médico; discurso pedagógico da Medicina; normas de gênero.

ब) Esta obra tem licença Creative Commons.
Bisturis, estetoscópios, macas, máscaras, luvas, seringas, agulhas, soro. Corredores extensos, paredes brancas com detalhes em azul, cantos de parede arredondados e pisos emborrachados, para facilitar a limpeza e contribuir com a higiene. Dispensores de álcool-gel, estrategicamente alocados na saída dos quartos abarrotados de pacientes, uma mistura de cheiros de hipoclorito de sódio e essência de lavanda, exalando do chão limpo. São expressões do inóspito ambiente de um hospital universitário, lugar no qual, segundo a literatura médica, o Ensino Médico se dá por excelência e, por conseguinte, o local primordial no qual uma/um boa/ bom médica/o é forjada/o. Qual a centralidade dos currículos médicos, ou, se quisermos dizer de outro modo, qual a centralidade de discursos, saberes, estruturas físicas arquitetônicas, 
' Fabíola ROHDEN, 2001, 2004; Sérgio CARRARA, Jane RUSSO e Lívia FARO, 2009

${ }^{2}$ Elizabeth MACEDO, 2004

${ }^{3}$ Michel FOUCAULT, 2010, p. 15. disposições diagramáticas de livros, abordagens clínicas diferenciadas na educação de médicas e médicos? Quais ferramentas e maquinários são utilizados para forjar aquele ou aquela que é o/a signatário/a irrestrito/a dos direitos e saberes sobre corpos, subjetividades, populações e comunidades? De que modo práticas pedagógicas de um currículo médico guardam relações com as normas de gênero? Como essas práticas regulam corpos ao dizer sobre certas formas de subjetividades generificadas no currículo da Medicina? Como a prática pedagógica médica valida e delimita fronteiras entre os gêneros e as geografias profissionais para a própria existência de médicas e médicos?

A nós, não parece restar nenhuma dúvida sobre os endereçamentos de gênero e sexualidade agenciados pelos discursos da Medicina. Uma vigorosa e vasta produção tem feito circular como esses discursos definem fronteiras, autorizam espaços, materializam corpos, normalizam condutas, confinam existências. ${ }^{1}$ Todavia, nosso foco, neste artigo, tem sido menos cartografar como os discursos médicos e biológicos marcam o gênero e a sexualidade, mas apontar como os discursos biomédicos não são, nem mais nem menos marcados por normas de gênero e sexualidade. Nosso objetivo, portanto, não é apenas explorar essa sorte de atravessamentos, mas investigar, mais especificamente, o discurso pedagógico da Medicina e o currículo médico. Referimo-nos à forma à forma que a educação médica, como prática cultural, busca constituir sujeitos generificados, sejam alunos/as, professores/ as e pacientes. Investigar, assim, de que modo o gênero marca o funcionamento do discurso pedagógico da Medicina em um currículo de formação médica.

A opção por designar o discurso pedagógico da Medicina apoia-se em dois deslocamentos circulantes no campo do currículo. Por um lado, procura estabelecer uma distinção entre a ciência médica, como campo de produção do conhecimento, e a ciência médica da educação médica. Julgamos tal distinção fundamental, não porque a primeira seja imune à cultura, mas porque a última tem compromissos não apenas com a "adequação" ou a "verdade" do conhecimento científico - mantendo todos esses termos já sob rasura -, mas também com projeções e finalidades sociais da profissionalização e da educação médica. Por outro lado, nesse sentido, permite pôr em relevo o currículo da Medicina como um híbrido cultural, ${ }^{2}$ composto por um movimento de recontextualização de uma série de textos e discursos ambivalentes, que não só não se esgotam nos discursos médicos, como não podem ser a eles reduzidos. Tal movimento permitiria abrir espaço para mapear os deslizamentos de sentidos que favorecem uma leitura da heterogeneidade de currículos médicos a fim de "pensar de outro modo"3 a ortodoxia de 
${ }^{4}$ Mary DOUGLAS, 1991.

5 Judith BUTLER, 1997.

${ }^{6}$ FOUCAULT, 2005.

7 Gilles DELEUZE, 2006.

${ }^{8}$ Elizabeth ELLSWORTH, 1997 ${ }^{9}$ Marlucy Alves PARAíSO, 2011 , p. 149.

${ }^{10}$ MACEDO, 2011. pensamento com a qual a Medicina tem sido descrita e caracterizada.

Entre uma e outra posição, figura um incômodo político: a tarefa de complexificar aquilo que Mary Douglas ${ }^{4}$ chamou, certa vez, de materialismo médico, como um convite a reconhecer que a relação entre nossos ritos simbólicos e nossa higiene é, algumas vezes, estranhamente estreita. Torcemos, doravante, um pouco essa proposta para, antes de pensar qualquer poluição alhures, observar como as nossas próprias ideias, mesmo as mais críticas sobre a Medicina, frequentemente, expulsam o perigo e se encontram dominadas pela patogenia e pela limpeza. Apesar de estarmos levantando considerações fundamentais, filiamo-nos àquilo apontado por Judith Butler: ${ }^{5}$ o risco de maximizar de modo inesperado o efeito do discurso que se pretende criticar ao reduzir o campo de significação e dirigir nossas estratégias de oposição para um cenário de hegemonia que é concebido como horizontal e homogêneo. À medida que deixamos de lado a própria precariedade dos discursos, tal como apontado por Michel Foucault, ${ }^{6}$ mais difícil torna-se a distinção entre os efeitos normativos dos discursos médicos e os horizontes imaginativos da ambivalência dos currículos de formação médica, e mais sólidas tornam-se as bases que convertem os currículos médicos em uma forma inequívoca de transposição do discurso médico.

Cartografar, deste modo, as marcas de gênero e sexualidade em um currículo de Medicina torna possível perguntar sobre as condições pelas quais a Medicina constitui objetos inteligíveis, mas, sob condições expostas, também permite apontar para os limites das referidas condições, os momentos de seus pontos de contingência e transformabilidade - ou, como diria Gilles Deleuze, ${ }^{7}$ seus pontos de gagueira. $O$ argumento desenvolvido, neste texto, é que o currículo da Medicina é constituído por um conjunto de discursos generificados, que posicionam sujeitos tanto articulados em torno de uma medicalização da moralidade sexual como de uma moralização sexual da Medicina. O currículo médico é, aqui, entendido como um produto cultural que busca endereçar aos sujeitos a que se destina, utilizando jogos narrativos que os localizam em um lugar social, ${ }^{8}$ um artefato que sinaliza como "podem ser, como devem proceder e o que devem tornar-se". ${ }^{9}$ Entretanto, como território cultural, sujeito à disputa e à interpretação, o currículo também é uma máquina instituinte de sentidos em um espaço submetido a fechamentos discursivos incapazes de total controle, uma enunciação marcada pela ambivalência que caracteriza qualquer enunciação. ${ }^{10}$ Logo, é um espaço que tanto seus limites inscrevem contornos com base na premissa unilinear sexo gênero-sexualidade, quanto os indica para seus pontos de contingência e de transformabilidade. 
${ }^{11}$ BUTLER, 2002 e 2010.

12 BUTLER, 2002.

${ }^{13}$ BUTLER, 2006.

14 Jeffrey WEEKS, 2000.

${ }^{15}$ BUTLER, 1997 e 2010.

Como é no âmbito dos discursos biomédicos que o mito do binarismo entre os sexos sustenta-se, julgamos relevante buscar entender como o currículo médico tem lidado com as posições de sujeito, criadas pela matriz normativa de gênero que é, segundo Butler, ${ }^{11}$ uma das formas de legislar sobre os corpos e de produzi-los, de qualificar um corpo para a vida no interior do domínio da inteligibilidade cultural. ${ }^{12}$ Gênero, portanto, é entendido como um conjunto de normas que regula a produção dos corpos e produz a ideia de corpos sexuados considerados naturais, o que produz a ideia de essências subjetivas. ${ }^{13}$ Sexualidade, por sua vez, figura neste artigo como a construção cultural, pela qual desejos e prazeres corporais são vividos, que prevê a formatação e a ordenação dessas funções, segundo um conjunto de regras e normas, variáveis de acordo com as épocas e as sociedades. ${ }^{14}$ Apoiamo-nos em Butler ${ }^{15}$ para defender que não apenas as posições de gênero e sexualidade são construídas discursivamente, mas também o sexo é uma ficção estrategicamente construída, um "ideal regulatório". ${ }^{16}$ Estamos, portanto, diante de um conjunto de conhecimentos e práticas que organizam a sociedade, generificando e sexualizando corpos, desejos, atos, identidades, relações sociais, culturas e instituições.

Ao reunir observações participantes, realizadas em um currículo de Medicina durante quatro semestres letivos, nosso objetivo foi o de compreender, em um currículo médico, como gênero e sexualidade são trazidos para as práticas pedagógicas e tornados parte do processo de formação educacional. ${ }^{17} \mathrm{E}$, a partir dessa compreensão, mostrar que sexualidade e gênero são da ordem da "reiteração das normas", ${ }^{18}$ qualificando corpos e sujeitos no interior de práticas pedagógicas, e de que modo são materializados como "reencenação e nova experiência de um conjunto de significados estabelecidos socialmente". ${ }^{19}$ Ao levar em conta a natureza situada, flexível e reflexiva da observação, ${ }^{20}$ nossa tarefa consistiu em acompanhar o dia a dia das atividades pedagógicas e clínicas de uma turma de Medicina, registrando, por meio da escrita em diário de campo, falas, ações, imagens, expressões, escritos, desenhos, disposição de objetos, de espaços e tempos. E, se aqui utilizamos uma linha de ação, depreendida da produção da analítica do discurso de Foucault, ${ }^{21}$ é porque tomamos pornecessário garimpar como funcionam os discursos de gênero e sexualidade no currículo médico, trazer à tona seu processo de feitura e seus efeitos, fazer novos arranjos com esses discursos para explicitar o que eles produzem e instituem.

As três partes que se seguem, descrevem e discutem como um currículo médico e seus sistemas de pensamento generificados "operam", como "funcionam", o que esse discurso "faz". ${ }^{22}$ Nossa orientação seguiu, assim, em torno de três

22 Nikolas ROSE, 1996. 
situações extraídas do diário de campo e que, atravessadas por outras situações observadas, colocam em foco as estratégias de funcionamentos de discursos generificados em um currículo médico. Com a primeira, assinalamos o posicionamento dos sujeitos-mulheres nos discursos médicos como um maquinário reprodutivo com bases em signos anatômicos cuja função é a perpetuação da espécie. A seguir, apontamos como corpos de alunos médicos e alunas médicas são relacionados, hierarquizados e valorados, tomando-se por base características construídas culturalmente de forma arbitrária sobre o masculino e o feminino e que devem pontuar as condutas pedagógicas e profissionais desses sujeitos. Por fim, comentamos como a medicalização dos modos de existir no mundo desdobra-se em uma moralização da sexualidade.

\section{Exemplo 1: A reprodução como destino}

Mais uma vez íamos àquele quarto que cheirava a álcool-gel, ataduras e desinfetante, o professor sempre à frente, passando irresoluto pelos longos corredores da Enfermaria, sem desvios de olhares para os quartos ao lado, abarrotados de doentes, que ficavam para trás. Chegamos ao quarto em questão, uma jovem senhora de no máximo 45 anos estava deitada, apesar do semblante levemente pálido, sua voz era firme e decidida, de uma forma a não denunciar o que ela vivera há algumas semanas atrás. O professor rapidamente, em tom seco e austero, estabeleceu um breve contato e percorrendo as folhas do prontuário da paciente constatou que ela estava ali devido a um quadro severo de câncer de mama, o que culminou na retirada de toda a mama esquerda. Sem mesuras, o professor então nos dá uma aula excepcional sobre neoplasias mamárias, na beira do leito da paciente, sob também sua atenta escuta, aula com direito a informações como expectativa de vida dos pacientes e taxa de reincidiva da doença. O professor, por fim, completa sua exposição com a seguinte assertiva: 'Esta senhora devia agradecer por estar viva, afinal, com essa idade ela não vai amamentar mais ninguém, agora é só esperar a equipe cirúrgica reconstituir a mama dela e ela vai voltar a ter uma vida normal' (Trecho do diário de campo).

O que essa narrativa diz e faz ver sobre o funcionamento dos discursos de gênero em um currículo médico? O seio da paciente representa meramente uma função biológica e reprodutiva de amamentação? Ou sua ausência diz algo sobre a inteligibilidade cultural dos corpos designados de mulheres? Na cultura ocidental moderna, as formas de se fazer Medicina se desenvolveram a partir de um modelo científico, positivista e mecanicista, enfatizando a dimensão 
${ }^{23}$ Mário Alfredo MARCO, 2003.

\footnotetext{
${ }^{24}$ Donna HARAWAY, 1999.
}

${ }^{25}$ Belinda DAVIS e Peter APPELBAUM, 2002. biológica sobre as dimensões psicológica e social, aquilo que a Medicina tem convencionado chamar de modelo biomédico. ${ }^{23} \mathrm{O}$ ser humano passa a ser tomado como uma máquina composta de partes independentes, a doença como defeito dessa máquina e o médico como mecânico que intervém fisicamente para consertar a avaria em questão.

"Agora é só esperar a equipe cirúrgica reconstituir a mama dela" - evoca e insere a posição do médico como uma espécie de mecânico do corpo e a paciente como um corpo que só é possível em suas partes e que, quando uma delas apresenta-se com defeito, cabe à Medicina restaurála. Cada uma destas partes desempenha, portanto, uma determinada função observável e independente, em que o conjunto do organismo é explicado pela soma das partes ou das propriedades. Todavia, esse jogo de enunciação tenta apagar seus efeitos discursivos e contingenciais, como se o dito sobre o corpo estivesse imune à significação simbólica e cultural. A própria enunciação põe em cena a articulação em torno do poder de significar o corpo como uma engenharia biológica. Permite antever o modo como essa leitura do corpo é um processo cultural em que o corpo humano aparece conceitualizado como um grande engenho cujas peças encaixam-se ordenadamente e segundo um processo racional.

Como o inimigo que deteriora a engenharia do corpo, a doença só é possível como uma avaria mecânica, uma espécie de aberração em uma máquina que funciona a pleno vapor. Mesmo como defeito, esse inimigo potencializa a promessa da terapêutica médica, já que cabe à Medicina consertá-la, mas, simultaneamente, também explicita sua impossibilidade, já que a intervenção deforma os limites humanos generificados do corpo. A referência feita a um corpo transumano, presente nas muitas metáforas em que o corpo humano é tomado como máquina ou comparável a outros objetos inanimados, e retratada em muitos dos livros-textos, tomados por básicos nas disciplinas, ao retirar o corpo de seus contextos culturais, na descrição de sua dimensão biológica em um processo mecânico de sistemas e órgãos, permite pensá-lo como um objeto manipulado de fora pela Medicina ciência. Não, sem trazer a contrapelo uma fantasia de infalibilidade, projetando um corpo perfeito, que, se perfeito fosse, não daria sentido à intervenção médica.

A distinção entre o animado e o inanimado que constituiu as fronteiras das ciências naturais na Modernidade, como caracteriza Donna Haraway, ${ }^{24}$ vê-se tanto reiterada como borrada no uso desse jogo de metáforas para a inscrição do lugar da Medicina no corpo. É, dessa forma, que o discurso universalista da ciência médica contribui tanto para a propagação de racismos e sexismos explícitos ${ }^{25}$ quanto para "o 
${ }^{26}$ Stuart HALL, 2003, p. 70

${ }^{27}$ Thomas LAQUEUR, 2001

${ }^{28}$ Londa SCHIEBINGER, 2004 ${ }^{29}$ WEEKS, 2000

${ }^{30}$ Georgia WARNKE, 2005.

${ }^{31}$ Renato VELOSO e Vanessa BEZERRA, 2004 fechamento discursivo de situações cotidianas", ${ }^{26}$ já que seu caráter de ciência, que se apresenta como imune à cultura, tem consequências para os endereçamentos de gênero e sexualidade. São esses discursos do maravilhoso mundo do corpo mecânico moderno que ajudaram a forjar a existência cultural de dois gêneros opostos e complementares entre si. ${ }^{27}$ No currículo investigado, o corpo a ser tratado como partes encaixáveis de um quebra-cabeça têm seus limites contornados pelo gênero e pela sexualidade quando os seios são descritos como mais uma dessas partes que singularizam a existência dos corpos, especificamente qualificados de mulheres, cuja única e exclusiva função é a amamentação. A mama tem, portanto, uma função biológica e reprodutiva. O fato de marcar a diferença homem/mulher apenas ao referir-se ao sistema reprodutor é uma constante na formação médica, expressando uma característica que, de acordo com Schiebinger, ${ }^{28}$ é uma das marcas da ciência. Como Weeks, ${ }^{29}$ consideramos que, ao destacar no corpo um ponto de articulação em torno do qual gênero e sexualidade são constituídos, não apenas se refere que seja por ele e através dele que o gênero inscreve-se, mas porque, no mundo contemporâneo, especialmente, em que uma suposta essência das identidades está sendo cada vez mais posta em xeque, o corpo acaba tornando-se uma referência tangível. Não ao acaso, o choque dos/as alunos/as diante de uma radiografia de seio de uma travesti na aula de mastologia irrompe. Outro professor, diante dos olhares estupefatos e das conclusões de que aquele seio radiografado não era o de uma mulher, dispara: "E quem foi que disse que só quem tem seio é mulher?". Esse movimento de deslocamento só se torna inteligível quando a travestilidade é expulsa da categoria mulher - a estratégia restritiva-, ou quando o seio continua a ser lido como uma propriedade do corpo feminino, seja mulher, seja travesti - a estratégia amplificadora. De um modo ou de outro, o corpo como lugar de articulação discursiva da inteligibilidade de gênero e da sexualidade persiste e insiste. Como demonstrou Warnke, ${ }^{30}$ são inúmeros os exemplos em que fica claro como o sexo biológico é uma construção, que oscila entre matrizes cromossomiais e anatômicas. Não ao acaso, quando as diferenças corporais de gênero são desvinculadas das estruturas sociais e dos sistemas simbólicos, os seios são tratados como propriedade individual, cuja perda a Medicina deve recompor. No entanto, como ressaltam Renato Veloso e Vanessa Bezerra, ${ }^{31}$ é preciso atentar-se que nos processos saúde e doença estão presentes diversas formas de poder que conferem especificidades ao adoecimento das mulheres, bem como outros fatores ligados às determinações de gênero. Diante da articulação entre seio, como parte de uma mecânica corporal generificada, e a biologia repro- 
${ }^{32}$ Marilyn YALOM, 1998, p. 18.

${ }^{33}$ BUTLER, 2002, p. 226. dutiva dos gêneros e sexualidades, "as mulheres têm sido obrigadas a confrontar-se com o significado do seio como fonte de vida e aniquilador". ${ }^{32}$ Ao mesmo tempo em que sua presença lhes confere a existência como tal, sua ausência ameaça a mesma possibilidade de viver. $O$ "agradecer por estar viva" e "reconstituir a vida normal" evoca o lugar estigmatizado do câncer de mama, mesmo no interior de um currículo médico, em que o recurso discursivo da biologização mecânica do corpo oblitera os mecanismos discursivos de uma doença associada às mutilações do feminino e que carrega consigo a ideia de culpa e castigo.

A retirada das marcas morfológicas designadas como femininas divulga uma espécie de efeito de terror sobre o corpo da mulher vir a deixar de sê-lo. Quando um seio se perde, cria-se uma mulher sem um atributo que faz parte da condição de ser construída enquanto tal. Tomar determinadas partes dos corpos dos sujeitos designados de mulher como funções meramente reprodutivas, ałualiza a legitimação dos discursos que generificam e valoram os indivíduos tomando por base certos atributos morfológicos. Contudo, paradoxalmente, é o próprio procedimento cirúrgico sobre o seio da paciente que insere uma quebra da imagem de corpo generificado que o próprio discurso médico ajuda a constituir. Se, por um lado, a ciência médica extrapola seus domínios e passa a definir comportamentos esperados das mulheres, o comportamento de mãe - aquela que cuida e alimenta - e como esse comportamento é reforçado pela naturalização das analogias construídas com as funções mecânicas do corpo; por outro lado, a mesma ciência, via intervenção cirúrgica, "mutila" esses significados ao evocar o lugar universal e a-histórico da terapêutica médica, de "consertar as peças com defeitos".

Em um só gesto, ao divulgar o lugar social da Medicina para médicas e médicos em reparar os defeitos de um corpo, a prática de ensino expõe a própria contingência do discurso médico que, ao intervir sobre o corpo, borra a fronteira dos gêneros que se propõe constituir. Como sugere Butler "um performativo 'funciona' na medida em que absorve e cobre as convenções constitutivas pelas quais é mobilizado". ${ }^{33} \mathrm{Ca}-$ beria, portanto, a esse corpo duplamente defeituoso, tanto em termos de saúde como em termos de gênero, recorrer à própria Medicina para a restauração de sua normalidade. Nesse sentido, a cirurgia reparadora não só constitui um retorno à normalidade do corpo doente, mas também, uma reparação da normalidade de gênero. Porém, esse mesmo jogo discursivo, que permitiria apagar os vestígios da contingência, expõe a que o discurso médico recorre, tanto quanto a cirurgia reparadora, para restaurar o gênero do corpo que o próprio exercício médico põe em suspensão. É com esse

786 Estudos Feministas, Florianópolis, 23(3): 779-801, setembro-dezembro/2015 
${ }^{34}$ Marina Fischer NUCCl, 2010; Emily MARTIN, 1996, 2006.

${ }^{35}$ Elizabeth GROSZ, 2000.

${ }^{36}$ Maria Izilda MATOS, 2003. sentido de ambivalência que as normas de gênero operam nos currículos médicos, colaborando na produção de corpos valorados no interior das práticas sociais.

Apoiando-se nessa naturalidade biológica, sempre sob rasura, são construídas especificidades e particularidades para os corpos designados de mulher, constituindo-a como um "outro" da Medicina, a quem cabe estudar de modo particular. ${ }^{34}$ Dessa forma, nesse currículo na organização das disciplinas, operam-se marcações discursivas distintas, a partir de tipos específicos de genitália, ${ }^{35}$ em que uma delas é lida como o padrão a ser estudado (masculino) e a outra como a diferença a ser incluída (feminino). Porém, esta não é uma realidade sem conflitos. Se no currículo investigado há uma mensagem explícita sobre a construção de uma diferença natural entre os corpos, o que implica na produção de um corpo particular às mulheres, ${ }^{36}$ à primeira vista parece curioso que tais qualidades possam revelar o corpo sexuado masculino em uma pedagogia concebida para evitar o seu aparecimento a todo o custo. Como modelo universal a ser estudado, o masculino é frequentemente um texto escrito muito conhecido e divulgado pela literatura médica que, portanto, não precisaria ser dito já que é supostamente partilhado por todos. No entanto, tal endereçamento na certeza do homem como sujeito universal do exercício e do estudo da Medicina insere fissuras sob um discurso de doença como defeito de máquina perfeita. Afinal, qualquer suposição de avaria no corpo masculino arrisca perder suas prerrogativas como corpo universal e expõe uma corporalidade que deveria ser apagada.

As distintas estratégias discursivas acionadas nesse currículo reiteram mecanismos generificados que corporificam de modo ambivalente sujeitos com base no discurso biológico. Ainda que esses corpos biológicos sejam interpretados como corpos distintos de um homem e de uma mulher heterossexual, isso acaba por reiterar uma visão biológica e higienista, pautada na reprodução; sua própria enunciação evoca, no mesmo movimento, como a Medicina tem uma pedagogia que, ao que parece, não é tão natural assim. Um discurso que tende a posicionar corpos generificados, como peças em maquinários reprodutivos, gerenciados pela Medicina a qual assume a função de garantir não só a saúde, como também a normalidade do gênero. Uma vez que a diferença entre os sexos é estabelecida, torna-se inevitável a vinculação entre sexo, gênero e sexualidade. Essa vinculação é amplificada pela generização de âmbitos do discurso pedagógico médico em que distinções de gênero não fariam, a priori, o menor sentido, tendo como correlato o ensino de atributos corretos e específicos que tornam inteligíveis dois tipos de corpos no interior da formação profissional médica. 
Os endereçamentos agenciados indicam a condensação de uma pluralidade de cambiações, nas quais o corpo sexuado tem, no currículo investigado, funcionado como ponto de disciplinamento das diferenças de gênero e sexualidade, emergindo como esta fabricação cultural de discursos biomédicos. Embora pareça ingênua e "apenas biológica", torna-se central na materialização do gênero na Medicina.

\section{Exemplo 2: Médicas estão para enfermel- ras, assim como a Medicina está para homens}

Era mais uma daquelas inúmeras aulas de Anatomia Humana que tínhamos durante a semana. Em um daqueles momentos nos quais o professor propositadamente foge do assunto para quebrar o ar monótono da aula e distrair os alunos, o debate acaba por tomar um rumo não muito usual e um tanto quanto diferente do esperado. 'Na balada, vocês, meninos, têm que dizer logo que fazem Medicina, pois quando elas sabem que vocês fazem Medicina todas elas querem alguma coisa, a mulherada cai matando, afinal não é todo dia que se pega um médico. Mas cuidado, viu? Essas são do tipo que sentam no colo e fazem filho'. As risadas altas e ressonantes provinham de todos os cantos e bocas da sala, e divertindo-se também com a situação, a professora insistia: 'Já vocês, meninas, não podem dizer logo que fazem Medicina, porque isso assusta os homens, vocês devem dizer primeiro que fazem Enfermagem, para só depois dizer que serão médicas, se não eles fogem'. Assim, era instruída, aquela turma do primeiro de doze períodos que ainda estariam por vir (Trecho do diário do campo).

O que a enunciação assinala quanto à dinâmica de construção de um discurso generificado em um currículo médico? Como pensar o lugar desses discursos generificados na formação de médicos e médicas? Esse discurso expressa como o ensino de conteúdos, saberes, conhecimentos, conceitos, habilidades, competências, culturas, valores, condutas, modos de ser, estar e viver, são marcados por conceitos

${ }^{37}$ PARAÍSO, 2011. estáveis de gênero e sexualidade. ${ }^{37} \mathrm{Um}$ discurso que valora modos de existir e trabalhar, os quais tornam inteligíveis determinadas posições corporificadas de médicas e médicos. Estabelece uma relação de valoração subalternizante entre médicos homens e médicas mulheres, cujas significações estão respectivamente conectadas a "arte de curar" - a Medicina - e a "arte de cuidar" - a enfermagem. Desta forma, entrelaça-se uma dupla articulação de gênero: uma que atribui ao feminino o lugar do cuidado e ao masculino o 
${ }^{38}$ Michelle PERROT, 2008.

${ }^{39}$ Margareth RAGO, 2009.

40 PERROT, 2008.

${ }^{41}$ PARAÍSO, 2011.

${ }^{42}$ Lívia CARDOSO, 2011. lugar da virilidade, ao mesmo tempo em que estabelece entre eles capacidades cognitivas diferentes. Nesse currículo, a visibilidade da mulher como sujeito da Medicina tende a desqualificá-la como boa parceira afetiva e sexual de um homem. No que pese a heterossexualidade presumida como destino da relação entre os gêneros, essa demanda encerra uma escolha hostil: ou se é uma "boa mulher", lida como aquela que consegue arranjar um parceiro homem; ou se é médica, dado que a formação profissional médica tende a depor contra a "natureza das mulheres".

Se seguirmos as pistas discursivas deste currículo, o desempenho bem-sucedido em Medicina apoia-se em um reiterado contraste entre a força para enfrentar os rigores do exercício médico, alheio, por pressuposto, à "sensibilidade feminina", e a inteligência cognitiva para dominar um repertório de conceitos e técnicas particulares, uma coisa que, se as mulheres detiverem, devem reter, a fim de não assustar seus pretensos parceiros afetivos e sexuais. Quando as demandas da ciência médica contemporânea exigem, ao mesmo tempo, características de ambos os gêneros tais como organização e racionalidade, habilidade manual e habilidade de abstração do pensamento, capacidade de cuidado e capacidade cognitiva, produz-se a possibilidade de sucesso profissional para todos/as os/as estudantes, independentemente do gênero que assumam. A lógica do cuidado como feminina é, então, acionada como uma estratégia para saturar o campo de significação diante da possibilidade de subversão aberta pelo próprio currículo da Medicina.

Desmontar essa verdade sobre os gêneros, suas aprendizagens e seus processos de educação, supõe, cartografarmos sua produção histórica e sua efetividade. Uma primeira possibilidade começa em apontar como a articulação entre cuidado e mulheres está endereçada nos mais diversos espaços. Nos escritórios, para as secretárias; ${ }^{38}$ nas fábricas, para as costureiras; ${ }^{39}$ nos hospitais, para as enfermeiras; ${ }^{40}$ nas políticas educacionais, para as professoras, ${ }^{41}$ nas salas de ciências, para as alunas. ${ }^{42}$ Esse encadeamento permitiria às mulheres médicas tornarem-se inteligíveis na vida social diante de homens, médicos ou não, desde que se portem como boas esposas. Quando se trata de formar médicas, trata-se também de formá-las para os papéis de mulher, dona de casa, esposa e mãe. Com efeito, não foram raras às vezes em que foram descritas e encorajadas como mais propensas à clínica médica e à saúde da família, especialidades que permitiriam associar o ritmo de trabalho com o cuidado da casa e o cuidado com a própria ideia de exercer a Medicina.

Outra possibilidade é mapear os antecedentes históricos da posição que afirma que as mulheres não possuem aptidão para raciocinar e documentar, para apurar como e 
${ }^{43}$ Joan W. SCOTT, 2005, p. 16.

${ }_{44}^{4}$ PERROT, 2008, p. 96.

${ }^{45}$ Marília Pinto CARVALHO, 2001.

${ }^{46}$ PARAÍSO, 2011.

${ }^{47}$ CARDOSO, 2011.

${ }^{48}$ Valerie WALKERDINE, 2007.

${ }^{49}$ BUTLER, 2006, p. 167.
${ }^{50}$ RAGO, 2001. por que os argumentos que a sustentam têm tal força agora. Esse discurso pode ser encontrado no final do século XVIII quando "havia psicólogos, médicos e filósofos que defendiam que as diferenças físicas de pele ou de órgãos corporais e qualificavam alguns indivíduos e outros não";43 ou nos fisiologistas do final do século XIX ao afirmarem que "as mulheres têm um cérebro menor, mais leve, menos denso". ${ }^{44}$ Reverberam, nos processos de avaliação escolar, ${ }^{45}$ nas políticas curriculares para alfabetização e letramento, ${ }^{46}$ no funcionamento de currículos das Ciências, ${ }^{47}$ na educação matemática ${ }^{48}$ que "distribui-se aos homens os direitos da fala plena e autorizada, negando-os às mulheres". ${ }^{49}$ Notadamente, esse lugar de fala não se revela nem se configura como uma verdade eterna, óbvia e inquestionável, precisa ser permanentemente produzido e conquistado ao se ensinar aos homens como modelarem seu corpo e ajustarem sua mente.

Descritos como aqueles que tendem a produzir evidência sobre o que é considerado como "expertise médica", homens portariam determinadas características peculiares, além de sua inteligência inata, que os autenticaria, para toda e qualquer especialidade médica, como que "naturalmente" nascidos para o exercício médico. Deste modo, a formação médica oferece a prova da virilidade dos homens e a marca de atração no mercado das relações de gênero. $E$, porque oferece a evidência de sua posição social e de sua inteligência cognitiva, faz todo o sentido expô-los nos roteiros de relações afetivas e sexuais. O currículo médico engendra um desejo que revela o performativo no próprio momento em que funciona. Os adornos encenados pelo currículo médico podem ser diferentes - incluindo tanto o jaleco branco e o estetoscópio, quanto um automóvel conversível mas o motivo de funcionamento é o mesmo. Como o aluno homem tem uma propensão quase natural para o exercício médico, o exercício de estudar Medicina só faz sentido caso corporificado em adereços e insígnias, capazes de traduzir e expor a formação médica para exigir seus privilégios de gênero.

Caso não obtenha sucesso no mercado das relações afetivo-sexuais foi apenas porque alguma mulher deu "o golpe da barriga", já que, a priori, o sucesso masculino como médico está garantido. A atribuição do não sucesso dos homens médicos a um golpe de "esperteza feminina" parece uma retomada das misóginas leituras médicas que, entre os séculos XIX e XX, dessexualizaram e patologizaram cientificamente o corpo da mulher..$^{50}$ Aquilo que é motivo de ostentação do homem no mercado das relações afetivo-sexuais funciona desqualificando duplamente as mulheres, tanto em termos cognitivos como em termos de relações sociais, encerrando a elas o lugar do cuidado. Entretanto, ao mesmo tempo 
${ }^{51}$ William PINAR, 2004

em que afirma as normas de gênero, o currículo chama a atenção para a performatividade do gênero ao confirmar que ela faz parte de um roteiro de relações entre corpos a ser reiterado. Ao expor sua dimensão contingencial e reiterativa, vê-se tanto enredado como curto-circuitando as armadilhas dos seus sistemas de pensamento. Ao adquirir efeito de verdade, normas de gênero acabam por moldar o modus operandi do encontro pedagógico do currículo da Medicina em que se investe na reiteração continuada dos sistemas de raciocínio, sem deixar de sinalizar o horizonte imaginativo de sua inteligibilidade.

As aptidões para a formação de alunas e alunos em Medicina não podem ser compreendidas à parte de considerações sobre gênero que são desenvolvidas e aceitas no interior de práticas sociais, como as pedagógicas, e servem como dispositivos que regulam essas práticas e afirmam dizer a verdade sobre os sujeitos. Um currículo de Medicina atua não apenas governando as normas que corporificam àqueles/as outros/as todos/as a quem a Medicina se destina, mas também gerindo os corpos dos médicos/as, permitindo seu reconhecimento no e pelo corpo biologizado e medicalizado como aquilo que são, com este ou aquele sujeito de gênero, dotado desta ou daquela conduta sexual. Com efeito, o currículo da Medicina não é uma coisa - um conjunto de conteúdos a serem ensinados ou uma lista de competências e comportamentos a serem aprendidos. Se, como sugere William Pinar, ${ }^{51}$ currículo é um movimento, então, antes de tudo, o currículo médico é um movimento constante e imparável de inscrição de corpos sexuados, sempre a serem conquistados, em uma matriz generificada de relações.

\section{Exemplo 3: Casada, porém do mundo!}

Naquela manhã já tínhamos atendido três pacientes e a senhora que agora entrava no consultório era a quarta de uma lista de muitos nomes. Ela tinha pouco mais de 50 anos, calçava um tamanco vermelho que marcava presença pelo toc-toc que fazia enquanto ela caminhava, usava uma minissaia jeans bem marcada e um decote a deixar à mostra a parte superior de seu sutiã também vermelho. A maquiagem era forte e vívida, um risco preto acima da pálpebra inferior, marcava seu olhar. E as pulseiras e anéis, inúmeros, brilhantes e vistosos, sempre anunciando qualquer movimento que ela fosse efetuar com as mãos. Um dos anéis se destacava, por ser uma grossa e dourada aliança no dedo anelar esquerdo. O médico, levemente desconcertado com sua presença, pigarreou um pouco e iniciou a anamnese. Ela queixava-se de um prurido genital. Médico: 'A senhora é casada?' Paciente: 'Sim'. Médico: 'Há quanto tempo?' Paciente: '20 anos'. 
52 Sandra Mara CORAZZA, 2002.

${ }^{53}$ Olivier FAURE, 2008, p. 53.

${ }^{54}$ Georges CANGUILHEM, 2007.

${ }^{55}$ Eliane Marta Teixeira LOPES, 2008, p. 15.

${ }^{56}$ Friedrich NIETZSCHE, 2007.
Médico: 'E nesse tempo de casada a senhora nunca... traiu seu marido?' Paciente: 'Nunca! Por quê?' Médico: 'Porque essa doença que eu acho que a senhora tem, até hoje eu só vi em mulheres do mundo'. Paciente: 'Como assim?' Médico: 'Nada, vou prescrever um creme vaginal e te encaminhar pra um ginecologista, que ele vai saber te orientar melhor' (Trecho do diário de campo).

O que se pode observar, em termos de noções de gênero e sexualidade no discurso do médico, protagonista, de mais uma observação deste currículo? O que autoriza e legitima essa conduta, essa forma de atuar, pensar e conjecturar? Ao que parece, as práticas médicas deste currículo se encontram marcadas num modo de fazer e exercer Medicina que evoca sentidos de moralidade, visto que o discurso pedagógico médico ensinaria a conhecer o bem e o mal. A própria determinação ética da pedagogia tem dado lugar ao juízo moral, submetendo os currículos à convenção do Bem e do Mal, ${ }^{52}$ que faz aproximar o discurso religioso do discurso médico no currículo da Medicina. Converte-se o jaleco branco em toga, e transforma-se o médico em juiz da moral e dos bons costumes, com legitimidade e autoridade para definir, decidir, deliberar e determinar como as questões de gênero e sexualidade devem ser moralmente tratadas. O discurso pedagógico médico articula, com efeito, "proteção de saúde com controle moral e social", ${ }^{53}$ para fazer da Medicina um baluarte da moral e dos bons costumes, guardiã da saúde, protegendo a população indefesa dos perigos provenientes do estado patológico. ${ }^{54} \mathrm{Um}$ currículo médico teria, então, a função de resguardar e vigiar as normas de gênero para, em sua "sagrada missão pedagógica", ${ }^{55}$ fazer voltar a elas todos aquelas/es que, por algum motivo, desviaram-se do normal, do saudável, do desejado.

A enunciação expõe como o discurso pedagógico da Medicina articula sentidos de moralidade, cuja genealogia tratada por Friedrich Nietzsche ${ }^{56}$ leva-nos a discursos cristãos, dando uma ambígua autoridade à Medicina em julgar e qualificar comportamentos, a partir de estigmas e estereótipos ampla e socioculturalmente construídos e difundidos. Um passo para confundir a tarefa de educar médicas/os com a tarefa de doutrinar corpos em uma matriz generificada de relações. Em meio às relações do currículo médico, a seleção do que ensinar envolve, também, os valores morais a divulgar e a definição do tipo de sujeito que quer se formar, em práticas discursivas e pedagógicas que "capacitam alguns a julgar e outros a serem julgados, alguns a curar e outros a serem curados, alguns a falar a verdade e outros a reconhecer sua autoridade e a abraçá-la, aspirá-la ou submeter-se a ela". ${ }^{77}$ Sua exigência em qualificar moralmente 
${ }^{58}$ BUTLER, 2002, p. 94.

${ }^{59}$ Richard MISKOLCl, 2007.

${ }^{60}$ Erich GOODE e Nachman BENYEHUDA, 2003

${ }^{61}$ FOUCAULT, 1992.

62 FOUCAULT, 2007, p. 180

${ }^{63}$ Francisca Luciana de AQUINO 2008.

${ }^{64}$ Cláudia FONSECA, 2004.

${ }^{65}$ Dagmar Estermann MEYER et al., 2004 . os sujeitos, em uma espécie de produção da pureza da norma de gênero, vê-se contaminada pelas impurezas de sistemas de crenças e valores morais que o discurso científico médico divulga como sendo necessário superar. Um jogo de dupla face: de um lado, moraliza-se a educação médica e a Medicina; de outro, medicaliza-se e cientificiza a educação moral.

O que seriam, pois as mulheres do mundo? Que divisão é essa entre mulheres do mundo e mulheres de casa? As mulheres do mundo são as que não estão em suas casas, cuidando dos afazeres domésticos? Quais seriam o local e o dever determinados à mulher em sua conjunção no espaço privado? O discurso pedagógico médico enraíza uma biologização de corpos generificados como correlata a uma moralização da sexualidade, delimitando os espaços para a atuação de corpos designados e considerados mulher. Aqui, mais uma vez, vê-se que tais atitudes e comportamentos são "performativos, no sentido de que a essência ou identidade que por outro lado pretendem expressar são fabricações manufaturadas e sustentadas por signos corpóreos e outros meios discursivos". ${ }^{58} \mathrm{O}$ julgamento moral da senhora, de quem é presumida uma pretensa "promiscuidade", a partir de vestimentas, gestuais e formas de portar-se, põe em cena como estes sinais apontam para a causa da enfermidade que a acomete.

Por um lado, o pânico moral utilizado no discurso médico visa culpabilizar e controlar grupos sociais estigmatizados, ${ }^{59}$ quando aquela senhora personifica e corporifica uma ameaça a posições, interesses, ideologias e valores morais dominantes. ${ }^{60}$ Por outro, reitera a máxima do dispositivo da sexualidade moderna: diz com quem fazes sexo e direi quem és. ${ }^{61}$ Isso remete às suas práticas sexuais, que não só definem quais os tipos de doença ela possa ter, mas também ao tipo de pessoa que ela deve ser. Sujeitos, então, seriam "destinados a um certo modo de viver ou morrer em função dos discursos verdadeiros que trazem consigo efeitos específicos de poder". ${ }^{62}$ Se a genitália, uma das engrenagens da máquina de generificação do corpo, é acometida por uma doença é porque foi submetida a uma espécie de uso moralmente inadequado para seu saudável funcionamento. A sexualidade feminina é qualificada na atualização de uma confluência de discursos que retomam o arcaísmo de uma moralidade expressa em um "eu" sexualmente autêntico sob a óptica do cuidado em saúde.

Denominar-se ou ser denominada como "mulher do mundo" é uma prática que se aproxima de uma moralidade que Francisca Luciana de Aquino, ${ }^{63}$ Cláudia Fonseca ${ }^{64}$ e Dagmar Estermann Meyer et al. ${ }^{65}$ identificaram em diferentes contextos junto a classes populares, quando se procura estabelecer fronteiras entre a mulher que "presta" e a que 
${ }^{66}$ FOUCAULT, 2008, p. 75.

${ }^{67}$ PARAÍSO, 2011, p. 158 "não presta". Nesse currículo, tal raciocínio indica que os corpos femininos que estão fora da ordem dessa moralidade, lidos a partir das roupas que portam, não só estão diretamente suscetíveis a certos tipos de doenças sexualmente transmissíveis como, por consequência, não podem "estar casadas". É o casamento que garante a inteligibilidade dos corpos femininos e, portanto, da qualidade da saúde de seu maquinário corporal, reiterando o lugar de confinamento ao qual corpos de mulheres estão designados e expondo que tipos de sanções esses corpos terão em sua saúde, caso escapem a essa lógica.

No que pese o fato da enunciação circular no currículo pela voz de médicos e médicas, o atravessamento entre moralidade, classe social, gênero e Medicina traz à tona o processo pelo qual a "normalização disciplinar consiste em primeiro colocar um modelo ótimo [...] e a operação da normalização disciplinar consiste em procurar tornar as pessoas, os gestos, os atos, conforme a esse modelo". ${ }^{66}$ Tal modo é, sobretudo, cientifizado por uma racionalidade médica que toma os corpos como objetos pedagógicos morais, ao passo que, os/as alunos/as médicos/as não apenas devem aprender conhecimentos médicos, mas também devem desenvolver uma moralidade médica quando olham tanto os seus corpos como os dos/as pacientes sob a lógica do juízo da moral. Endereçamento que evidencia a ausência de autonomia do discurso pedagógico médico, materializado nos currículos de formação profissional, em relação às categorias e aos valores dominantes da racionalidade moral e suas normas de gênero.

O currículo da Medicina não é, deste modo, composto apenas por saberes, propriamente médicos, sem que se colem a ele discursos morais, de cunho religioso, de traços sexistas, formando um jogo de significação cultural que tanto delineia, direciona e norteia os modos de agir e ver a Medicina, como torna complexa e heterogênea a formação pedagógica de médicas e médicos. Formação que, se não pode deixar de lado os discursos médicos e biológicos, não permite perder de vista suas recontextualizações no currículo médico, nem ter seu campo discursivo neles esgotado. Discursos que suplementam os discursos médicos, transformando-os, para endereçar formas de como os corpos femininos devem ser geridos explicitando as penas e as consequências de seu uso inadequado, consequências representadas por gestações inoportunas, doenças sexualmente transmissíveis ou até um câncer de mama-ao mesmo tempo que trabalham para apagar a corporalidade masculina a fim de ascendê-la como sujeito universal do estudo e do exercício médico.

Deste modo, o currículo médico trata-se de um importante espaço, em que "marcas produtivas de gênero marcam sua presença" ${ }^{67}$ para ensinar o certo, o errado, o esperado, o 
adequado, o inadequado, o normal, o anormal, o estranho e o "abjeto", o bom e o mal, em relação às posições dos corpos generificados. Nele, se a doença é um estigma, sobre ela atravessam traços de gênero que pesam sobre a mulher o lugar da culpa, corroborado, por outro lado, e em complementaridade, com a biologização dos corpos e das normas de gênero, que designa às mulheres um lugar sexualmente adequado e socialmente aceitável. Obviamente, um portarse fora dessa lógica, como sugere as roupas inadequadas da senhora para uma mulher casada, não é só um romper com as regras sociais. Implica desrespeitar a própria lei da natureza biológica do corpo das mulheres e, por consequência, pôr em questão os fundamentos contingenciais do discurso médico. O jogo entre a moralização da Medicina e a medicalização da moral constitui, deste modo, o coração do discurso pedagógico médico.

\section{À guisa de uma conclusão}

Estão todos lá, os sistemas binários, as normas de gênero, o dispositivo da sexualidade, a matriz heteronormativa e os sistemas de raciocínio hierarquizantes, deslizando e transpondo sentidos, num jogo discursivo cambiante. Assim, mesmo que as marcas de gênero permeiem e atravessem constantemente a prática pedagógica médica, o currículo médico analisado, a todo o momento, vê-se diante dos pontos em que sua precariedade é exposta. O poder da Medicina em nomear, descrever e qualificar, para instituir modos que permitem que nos narremos e que façamos determinadas coisas com nossos corpos, a partir de noções binárias que criam gêneros distintos, fundamentando-se na morfologia dos corpos, não se faz menos sem o poder de instituir o lugar da Medicina na paisagem social e de fazer deslizar as fronteiras do discurso que seria imune à cultura, ao social e ao simbólico. Quando se divulga uma taxonomia de corpos generificados que medicaliza sujeitos, a partir de suas condutas de gênero e sexualidade, enfrenta-se a inscrição, desde já, destas posições como disputas culturais arbitrárias para existir de uma ou de outra forma. Portanto, discursos médicos e biológicos não apenas marcam os gêneros e as sexualidades atravessando práticas culturais, mas apontam como os próprios discursos, disso que ensaiamos chamar de pedagogia médica, são, eles mesmos, nem mais nem menos, aparatos de cultura. Nessa direção, a indicação de que a Medicina, ou pelo menos a educação médica, talvez não seja tão biomédica assim, faz com que nossa premissa retorne como consideração. Se partimos de certo pressuposto para o qual a educação médica não opera só com base no discurso médico, permitimo-nos afirmar que o modo como este discurso 
${ }^{68}$ Gayatri SPIVAK, 1994, p. 204.

pedagógico médico opera, complexifica a relação entre gênero e educação médica, ao reinscrever em um cenário de impurezas aquilo que o discurso médico tenta expurgar. Esta é uma disposição para apontar a impossibilidade de construir um currículo que seja o negativo de tudo que foi exposto, pois as marcas de gênero, deixadas por tantas narrativas e discursos, nunca serão totalmente apagadas. Entendemos nosso trabalho diante dos currículos da Medicina, como um espaço que, como defende Spivak, 68 "torne visíveis as lacunas dos slogans do iluminismo europeu - nacionalismo, internacionalismo, secularismo, culturalismo, baluartes do nativismo - sem participar em sua destruição". Nesse espaço e tempo da educação médica, sempre em disputa, formas de significação estabelecem-se e corpos são forjados num terreno movediço. Ainda que, em algumas situações, o discurso pedagógico da Medicina mantenha a fantasia de um significado fixo, cabal, ele nunca será totalmente apreensível. É antes uma temporalidade em que elementos antagônicos e até mesmo contraditórios articulam-se sem a perspectiva da superação, criando espaços nos quais polaridades positivas ou negativas, ainda que relativas, não se justificam.

Em um mundo, como o da Medicina, descrito por discursos homogêneos, por hegemonias que não se admitem transitórias, pode ser potente apostar em como suas categorias são deslizantes, rearticuladas por elementos que supostamente não as constituem, contestando os territórios definidos por cada um e para si. Não implica, com isso, desconsiderar as estratégias médicas que visam à atualização das normas de gênero no poder de colonizar os corpos. Ainda que não seja absoluto, a normalização de gênero não pode ser desprezada em suas estratégias de confinamento de corpos ao reduzir a diferença ao mesmo essencializado em uma matriz generificada de relações. Uma redução que busca controlar a ambivalência da normalização, fechando a possibilidade de resistência. No entanto, é também verdade que esse mesmo currículo, por sua própria natureza híbrida, cria regiões de fronteira em que se torna obrigatório negociar o inegociável. Nessas zonas, reside a aposta política para lutar contra as formas de sujeição de gênero e sexualidade que a própria Medicina institui; nelas, podemos ressignificar as formas de se fazer, ver e sentir a Medicina na sua história, em suas ambivalências e impurezas, desfazendo-se dos discursos que generificam e sexualizam os corpos e investindo em novas formas de organização do saber médico, que levem em conta outros discursos e, ao mesmo tempo, desnaturalizem o discurso biológico e sua sistemática valoração de corpos pelo gênero. Afinal, se levarmos até as últimas consequências uma das lições da biologia e da Medicina, esses corpos normalizados, essas redes de sentido expropriadas, esses territórios existen-

796 Estudos Feministas, Florianópolis, 23(3): 779-801, setembro-dezembro/2015 
ciais disciplinados e generificados, essas formas de vida visadas no e pelo biológico não constituem uma massa inerte e passiva, mas um conjunto vivo de estratégias para a qual a própria educação médica também oferece potências de resistência.

\section{Referências}

AQUINO, Francisca Luciana de. Homens 'cornos' e mulheres 'gaieiras': infidelidade conjugal, honra, humor e fofoca num bairro popular de Recife-PE. 2008. 160 f. Dissertação (Mestrado em Antropologia) - Programa de Pós-Graduação em Antropologia, Universidade Federal de Pernambuco, Recife, 2008.

BOELLSTORFF, Tom. "Queer Techne: Tow Theses on Methodology and Queer Studies". In: BROWNE, Kath; NASH, Catherine (Org.). Queer Methods and Methodologies: Intersecting Queer Theories and Social Science Research. Surrey: Ashgate, 2010. p. 215-230.

BUTLER, Judith. Excitable Speech: A Politics of the Performative. Nova York: Routledge, 1997.

Cuerpos que importan. Sobre los límites materiales y discursivos del 'sexo'. Traducción de Alcíra Bixio. Buenos Aires: Paidós, 2002.

Deshacer el gênero. Traducción de Patricia SoleyBeltran. Buenos Aires: Paidós, 2006.

Problemas de gênero: feminismo e subversão da identidade. Tradução de Renato Aguiar. Rio de Janeiro: Civilização Brasileira, 2010.

CANGUILHEM, Georges. O normal e o patológico. Tradução de Maria Thereza Redig de Carvalho Barrocas. Rio de Janeiro: Forense Universitária, 2007.

CARDOSO, Lívia. "Conflitos de uma bruta-flor: governo e quereres de gênero e sexualidade no currículo do fazer experimental". In: PRÊMIO CONSTRUINDO A IGUALDADE DE GÊNERO 7. [Trabalhos apresentados]. Brasília: Secretaria de Políticas Públicas para Mulheres, Presidência da República, 2011. p. 39-60.

CARRARA, Sérgio; RUSSO, Jane; FARO, Lívia. "A política de atenção à saúde do homem no Brasil: os paradoxos da medicalização do corpo masculino". Physis, v. 19, n. 3, p. 659-678, 2009.

CARVALHO, Marília Pinto. "Mau aluno, boa aluna? Como as professoras avaliam meninos e meninas". Revista Estudos Feministas, v. 9, n. 2, p. 554-574, 2001. Disponível em: http://www.scielo.br/pdf/ref/v9n2/8640. Acesso em: 15 jul. 2013.

CORAZZA, Sandra Mara. Para uma filosofia do inferno na educação: Nietzsche, Deleuze e outros malditos afins. Belo Horizonte: Autêntica, 2002. 
DAVIS, Belinda; APPELBAUM, Peter. "Post-Holocaust Science Education”. In: MORRIS, Marla; WEAVER, John (Org.). Difficult Memories. New York: Peter Lang, 2002. p. 171-190.

DELEUZE, Gilles. Crítica e clínica. Tradução de Peter Pál Pelbart. São Paulo: Ed. 34, 2006.

DOUGLAS, Mary. Pureza e perigo: ensaio sobre a noção de poluição e tabu. Tradução de Sónia Pereira da Silva. Lisboa: Edições 70, 1991. (Col. Perspectivas do Homem, n. 39)

ELLSWORTH, Elizabeth. Teaching Positions: Difference, Pedagogy and the Power of Address. Nova York: Teachers College Press, 1997.

FAURE, Olivier. "O olhar dos medicos". In: CORBIN, Alain; COURTINE, Jean-Jacques; VIGARELLO, Georges (Org.). História do corpo: da Revolução à Grande Guerra. Tradução de João Batista Kreuch, Jaime Clasen. Revisão da tradução de Ephrain Ferreira Alves. Petrópolis: Vozes, 2008. parte I, cap. I, p. 13-56.

FONSECA, Cláudia. Família, fofoca e honra: etnografia de relações de gênero em grupos populares. Porto Alegre: Edufrgs, 2004.

FOUCAULT, Michel. História da sexualidade I: a vontade de saber. Tradução de Maria Thereza da Costa Albuquerque e J. A. Guilhon Albuquerque. Rio de Janeiro: Graal, 1992. . A ordem do discurso. Tradução de Laura Fraga de Almeida Sampaio. São Paulo: Loiola, 1996.

. A arqueologia do saber. Tradução de Luiz Felipe Baeta Neves. Rio de Janeiro: Forense Universitária, 2005. "Soberania e disciplina". In: . Microfísica do poder. Organização, introdução e revisão técnica de Roberto Machado. Rio de Janeiro: Graal, 2007. p. 179192.

Segurança, território, população. Curso dado no Collège de France (1977-1978). Tradução de Eduardo Brandão. São Paulo: Martins Fontes, 2008.

. História da sexualidade ll: o uso dos prazeres. Tradução de Maria Thereza da Costa Albuquerque e J. A. Guilhon Albuquerque. Rio de Janeiro: Graal, 2010.

GOODE, Erich; BEN-YEHUDA, Nachman. Moral Panics. The Social Construction of Deviance. Malden: Blackwell Publishing, 2003.

GROSZ, Elizabeth. "Corpos reconfigurados". Cadernos Pagu, n. 11, p. 45-86, 2000.

HALL, Stuart. Da diáspora: identidades e mediações culturais. Organização de Liv Sovik. Tradução de Adelaine La Guardia Resende. Belo Horizonte: Editora UFMG, 2003.

HARAWAY, Donna. "A Cyborg Manifesto: Science Technology and Socialist Feminism in the Late Twentieth Century". In: HOPKINS, Patrick. (Ed.). Sex/Machine: Readings in Culture, 
Gender and Technology. Indiana: Indiana University Press, 1999. p. 434-467

LAQUEUR, Thomas. Inventando o sexo: corpo e gênero dos gregos a Freud. Tradução de Vera Whately. Rio de Janeiro: Relume-Dumará, 2001.

LOPES, Eliane Marta Teixeira. Da sagrada missão pedagógica. Bragança Paulista: Editora Universitária São Francisco, 2003.

MACEDO, Elizabeth. "Currículo e hibridismo: para politizar o conceito de cultura". Educação em Foco, v. 8, n. 1-2, p. 13-30, 2004.

"Curriculum as Enunciation". In: PINAR, William (Org.). Curriculum Studies in Brasil. New York: Palgrave Macmillan, 2011. p. 135-154.

MARCO, Mário Alfredo (Org.). A face humana da medicina: do modelo biomédico ao modelo biopsicossocial. São Paulo: Casa do Psicólogo, 2003.

MARTIN, Emily. The Egg and the Sperm: How Science has Constructed a Romance based on Stereotypical MaleFemale Roles. New York: Oxford University Press, 1996. . A mulher no corpo: uma análise cultural da reprodução. Tradução de Júlio Bandeira. Rio de Janeiro: Garamond, 2006.

MATOS, Maria Izilda Santos de. "Delineando corpos: as representações do feminino e do masculino no discurso médico". In: MATOS, Maria Izilda Santos de; SOIHET, Rachel (Org.). O corpo feminino em debate. São Paulo: Unesp, 2003. p. 107-128.

MEYER, Dagmar Estermann et al. "'Mulher sem-vergonha' 'e traidor responsável': problematizando representações de gênero em anúncios televisivos oficiais de prevenção ao HIV/AIDS". Revista Estudos Feministas, v. 12, n. 2, p. 51 76, 2004. Disponível em: http://www.scielo.br/pdf/ref/ v12n2/23960.pdf. Acesso em: 14 jul. 2013.

MISKOLCl, Richard. "Pânicos morais e controle social: reflexões sobre o casamento gay". Cadernos Pagu, n. 28, p. 101102, 2007.

NIETZSCHE, Friedrich. Genealogia da moral. Tradução de Paulo César de Souza. São Paulo: Companhia das Letras, 2007.

NUCCl, Marina Fischer. "O sexo do cérebro: uma análise sobre gênero e ciência". In: PRÊMIO CONSTRUINDO A IGUALDADE DE GÊNERO 6. [Trabalhos apresentados]. Brasília: Secretaria de Políticas Públicas para Mulheres, Presidência da República, 2010. p. 31-56.

PARAíSO, Marlucy Alves. "Raciocínios generificados no currículo escolar e possibilidades de aprender". In: LEITE, Carlinda et al. (Org.). Políticas, fundamentos e práticas do currículo. Porto: Porto Editora, 201 1. p. 147-160.

PERROT, Michelle. Minha história das mulheres. Tradução 
de Ângela M. S. Corrêa. São Paulo: Contexto, 2008.

PINAR, William. What is Curriculum Theory? Mahwah: Laurence Erlbaum, 2004.

RAGO, Margareth. "Feminizar é preciso: por uma cultura filógina". São Paulo em Perspectiva, v. 15, n. 3, p. 58-66, 2001. . "Trabalho feminino e sexualidade". In: DEL PRIORE, Mary (Org.). História das mulheres no Brasil. São Paulo: Contexto, 2009. p. 578-605.

ROHDEN, Fabíola. Uma ciência da diferença: sexo e gênero na medicina da mulher. Rio de Janeiro: Editora Fiocruz, 2001.

. "A obsessão da medicina com a questão da diferença entre os sexos". In: PISCITELLI, Adriana; GREGORI, Maria Filomena; CARRARA, Sérgio (Org.). Sexualidade e saberes: convenções e fronteiras. Rio de Janeiro: Garamond, 2004. p. 183-196.

ROSE, Nikolas. Inventing our Selves: Psychology, Power, and Personhood. Cambridge: Cambridge University Press, 1996.

SCOTT, W. Joan. "O enigma da igualdade". Tradução de Jó Klanovicz e Susana Bornéo Funck. Revista Estudos Feministas, v. 13, n. 1, p. 11-31, 2005. Disponível em: http://www. scielo.br/pdf/ref/v13n1/a02v13n1 .pdf. Acesso em: 20 jul. 2013.

SCHIEBINGER, Londa. Nature's Body: Gender in the Making of Modern Science. New Brunswick: Rutgers University Press, 2004.

SPIVAK, Gayatri. "Quem reivindica a alteridade?" Tradução de Patricia Silveira de Farias. In: HOLANDA, Heloísa Buarque de (Org.). Tendências e impasses. Rio de Janeiro: Rocco, 1994. p. 187-205.

VELOSO, Renato; BEZERRA, Vanessa. "Gênero e sociedade: uma breve introdução à dimensão de gênero nas relações sociais". Revista Teoria e Sociedade, v. 1, n. 12, p. 106-125, 2004.

WARNKE, Georgia. "Race, Gender and Antiessentialist Politics". Signs: Journal of Women in Culture and Society, v. 31, n. 1, p. 93-116, 2005.

WALKERDINE, Valerie. "Ciência, razão e a mente feminina". Educação e Realidade, v. 32, n. 1, p. 7-24, 2007.[Traduzido do original: Science, Reason and the Female Mind. London: Falmer Press, 1998.]

WEEKS, Jeffrey. "O corpo e a sexualidade". In: LOURO, Guacira Lopes (Org.). O corpo educado: pedagogias da sexualidade. Traduções de Tomaz Tadeu da Silva. Belo Horizonte: Autêntica, 2000. p. 35-82.

YALOM, Marilyn. História do seio. Tradução de Maria Augusta Júdice. Lisboa: Teorema, 1998. 
[Recebido em 15 de dezembro de 2013 , reapresentado em 22 de fevereiro de 2015 e aceito para publicação em 17 de março de 2015]

On how to Educate Male and Female Physicians: Marks Gender in a Curriculum of Medicine

Abstract: This article investigates how gender norms mark the functioning of the pedagogical discourse of Medicine in a curriculum of medical training. From participant observations added to a line of action inspired by the analytic discourse of Michel Foucault, it is argued that the curriculum of Medicine consists of a set of discourses that position gendered bodies articulating them around a medicalization of morality sex as a sexual moralizing Medicine. When connecting reproduction, cognitive abilities and processes of health care in gendered relationship matrix, this paper explores, thus, how discourse strategies supplement and transform the medical horizon conceived as homogeneous and stable in a set of meanings that indicate that Medicine, or at least medical education, perhaps not be as biomedical as well.

Key Words: Medical Curriculum; Pedagogical Discourse of Medicine; Norms of Gender. 